\title{
Engineering, Patriarchy, ANd the Pluriverse: What WORLD OF MANY WORLDS DO WE DESIGN? WHAT WORLDS DO WE TEACH?
}

\author{
Stephanie Mutch, Matt Borland, Kate Mercer \\ Systems Design Engineering, Library, University of Waterloo \\ smutch5@uwo.ca, mjborlan@uwaterloo.ca, kate.mercer@uwaterloo.ca,
}

\begin{abstract}
This paper presents a brief review of sustainability definitions and analyzes ways of designing taught in our Engineering education system, specifically acknowledging the capitalist, patriarchal, colonial, Western world that much, if not most, of current Engineering practice situates itself within. Included in these frameworks are pluriversal design, co-design, participatory design, and discursive design. Another important topic that will be examined is the dualist perspective embodied in Engineering practice that creates a distinction between "man" and "nature".

While this problem is inherently systemic, our intention is to provide a partial record of our own critical selfreflection, contextualized using critical theory. It is intended as a starting place for settler-descendent North American educators to begin to contextualize our own approaches, not as a way for us to guide steps forward, but instead to begin a self-critique of current approaches that need continued work.
\end{abstract}

Keywords: Sustainability, Ethics, Education, Critical theory, Engineering design, Professional engineer

\section{Acknowledgements}

The authors acknowledge that we live and work on the traditional territory of the Neutral, Anishinaabeg and Haudenosaunee peoples. The University of Waterloo is situated on the Haldimand Tract, the land promised to the Six Nations that includes ten kilometres on each side of the Grand River. Our ability to be working and living here now-in Canada-is a direct benefit of policies of expulsion and assimilation of Indigenous peoples during the time of settlement and Confederation, and since. The harms of these policies are many and are still being felt in Indigenous communities today. While the authors come from different backgrounds, we do also recognize that we have benefitted from the structures of white supremacy, settler colonialism, and patriarchy. It can be uncomfortable to acknowledge the systems in place, especially when one's own diverse personal lived experiences are layered and complex, our ultimate goals are to (1) begin to critique our own approaches, and (2) begin a conversation through demonstrating the complexity of aligning terminology and approaches.

\section{INTRODUCTION}

As Engineering educators, we need to remember that our actions are grounded within a historical context. The existing system of thought in the modern Western world, inclusive of industry, economy, and society is one that obliterated cultures, people, and ways of living through extractive globalization and colonization[1], [2]. While ignorance around this is not usually intentional, it is not ethical to ignore this legacy. We must remain aware that intention bears no weight on the consequences faced by people and the planet. Historically, development has come at the cost of resource extraction, violence, and cultural elimination in the advancement of modernity [3]. Issues and complexities around sustainability will not be resolved by a short conference paper, and we acknowledge that there is not a single formally accepted definition of sustainability that will work for every situation[4]. The Engineer's role in the modern Western world's technologically based lifestyle means that we have a particularly strong effect on the world, an effect that can be mediated through the way we design and produce the technologies that are part of our daily lives. As educators, we can inform and instill those design practices and values which the next generation of Engineers will use to create our technological world. The question then becomes, what set of values do we explicitly and implicitly present to our students when we teach Engineering, and in particular, design? If we don't explicitly choose values to teach, which ones are already implicitly part of our curriculums?

There has been significant and impactful work towards understanding and developing sustainable systems of thought, commerce, culture, and environment, and it's within this context that we can see that sustainability at its core isn't a technological problem, it's a consumption problem, where more technology is unlikely to be able to address the entirety of the systemic problems created by "development", modernization, and the endless advancement of technology [5]-[7]. Engineers have played a large part in the rapid spread of the unsustainable modern 
world; it is our thesis that instead of continuing with the ERTW (Engineers Rule The World) mindset, that a plurality of knowledge, perspectives, and ways of being need to be respected and embraced as being valuable in the education of our Engineering students.

Critical social theory provides a pre-existing analytical framework and body of literature that we can use to guide self-reflection and help us better understand the systems we work within as Engineering educators. The critical perspective aims to understand society based on how power is distributed among different groups of people [8]. It assumes that things are not what they seem, as there are always hidden power struggles at work behind the scenes [9]. These hidden power struggles result in the perceived reality in which we live. By taking a skeptical view of this surface level understanding we can better understand power - who has it, who doesn't have it, and how that shapes our world. If we can understand how these power relationships work we can better understand how a system works. If we don't understand these underlying relationships and power dynamics, we can't fully understand a system's overall behaviour. If we rely on surface level assumptions, rather than incorporating the full complexity of a system's interconnections and hidden relationships, we will always struggle to adequately represent and understand the full complexity and nuance of the system's resulting behaviours.

Ailton Krenak provides a simple definition of sustainability in his aptly titled book "Ideas to Postpone the End of the World". He simply asks if we can call ourselves sustainable if we take out more from the earth than we put back in [10]. As a member of the Krenak people, an Indigenous group from Eastern Brazil, Krenak acknowledges that even his community is not sustainable "because we can't provide for all our needs in a way that is fully integrated with the land. No community that is in debt to the land can call itself sustainable". Part of this unsustainability is the reliance of the community on water being trucked in to support their daily needs. A mine upriver from their village, a mine made possible and necessary through the work of Engineers of many disciplines and many decades of technological development and consumption, stored waste products in a tailings pond. That tailings pond burst and polluted the Rio Doce, the river the Krenak people had seen as a partner in their lives that supplied water, food, and transportation. Their system of existence was disrupted by the need of the modern world to extract resources for our own consumption. In this example we can see the unintended consequences that Engineers need to pay attention to if we want to truly offset our impact on the planet. We should be able to do the simple math and should understand that impacts throughout the entire lifecycle of the things we design, develop, manufacture, use, and throw away need to be considered. Krenak's basic definition of putting more back into the earth than we take out is a high bar to meet as a cradle-to-cradle perspective that offsets all the acts of consumption in the work that we do and the work our students will do[11]. If we truly want to get back to putting back in more than we take out, we also need to offset all that has been extracted by those that came before us that had been borrowed against our future.

As we teach the next generations of Engineers, we must begin to question our own assumptions, challenge ourselves on our mindset, and become self-critical in how and why we do things the way we do. Specifically, we need to ask ourselves (1) what our role is in this system and how do we approach sustainability as a topic in our courses; (2) how has the patriarchal system of knowledge we hold advanced degrees in shaped our view of the world; and (3) how are we passing on the best and worst aspects of this system of knowledge to our students? This paper will be discussing an all too brief overview of several definitions of sustainability, opening a discourse on how we teach Engineering and design, and ultimately how to start learning and expanding our perspectives in these areas so we can work to better understand cultures, places, and ways of being other than our own.

One perspective that attempts to recognize and address these issues and their systemic roots is "pluriversality" [1]. The pluriversal viewpoint sees sustainability as being not just something nice to have, but as necessary for our longterm survival, with that survival being something which is very much at risk if we continue to spread the values and power systems of the modern Western world to all the corners of the earth. There are two central ideas to this pluriversal perspective: that the dualism the modern world embraces to draw a clean line between "man" and "nature" is fallacious; and that the world is not one world, but instead a world of many worlds[12]. Proposing a nondualist world view challenges the basis for man's ("man" used intentionally) superior place in the ecosystem we are part of, and, intertwined inextricably with. Humans and nature are not two distinct things in this worldview, they are one and the same.

The Engineer has spent much of the last century in a "race against nature" that is of our own construction, one that has often been run alongside colonization and all its associated pitfalls [13]. In the pluriversal perspective this race against nature needs to stop so that we can all survive. The all here is not just all humanity, but all of nature. This means including the mountain and stream, parts of nature that some Indigenous groups extend personhood to in a sign of mutual respect that now even some governments are formally recognizing [14], [15]. Building on top of this non-dualist view comes the recognition that the world is made up of many worlds which all deserve the right to coexist. The language of a "world of many worlds" is intentional, implying that there is no singular set of values, beliefs, or understanding that is superior or has the right to be imposed on other "worlds". There is not one common world, but instead many worlds that deserve autonomy and 
sovereignty. Our colonial history has been the basic premise for the extractive globalization that has fueled the modern Western world, a world built, in part, by the Engineer. Escobar argues that for humans to survive, and that is truly what is at stake, survival; we need to face the full consequences of our colonial past and reinstate Indigenous sovereignty and autonomy around the world so that our future can be designed with the unique needs and values of nature and the pluriverse of communities around the planet [1].

As we move through trying to more deeply understand potential alternatives, both to pass on knowledge and discuss how to change a system, we first need to foundationally understand the alternatives - what are different definitions of sustainability; how can we better use existing knowledge of other fields and people; what are different ways to teach Engineering and design; and how can we better understand cultures, places, and ways of being so we can move beyond the built-in biases and assumptions of our world and be more intentional in our actions?

\section{Critical Theory}

As we begin to reflect on how historically dominant ideologies like white supremacy, colonialism, and patriarchy continue to manifest in the field of Engineering, we should look to the social sciences for guidance. Critical social theorists have been investigating these types of questions since the early 20th century, amassing a large body of literature and creating analytical frameworks that we can use as a starting place for our own reflections. Adopting a critical perspective can help Engineering educators to become more sensitive to how systemic inequality manifests itself in their institutions and in their classrooms.

Critical theory can be understood as a philosophy, paradigm, or perspective that views the world as made up of a series of power relations [8]. For critical theorists, everything in society, from the structure of our institutions, to our commonly held knowledge, is shaped and influenced by the distribution of power. Historically, wealthy, white, colonial males have held the most power in society and maintained this dominant status through the exploitation and oppression of others. In many ways, this legacy of inequality is still readily apparent in modern society, but critical theory suggests this power struggle also plays out in less obvious ways [9]. By encouraging researchers to investigate whose interests are served by the status quo, and whose interests are habitually ignored, critical theory seeks to expose entrenched systems of inequality and give a voice to the voiceless [17].

To perform a critical analysis, researchers are encouraged to "make strange," or approach taken-forgranted systems and knowledge with suspicion, rejecting surface level explanations [8], [9]. For example, critical theorists might pay close attention to the language that is used to describe and explain an issue or concept, critically assessing how it has been framed [8]. Whose perspective or worldview is represented? Is there room for other interpretations? If the issue or concept is framed in this way, will any individual or group stand to benefit or suffer disproportionately? By asking questions like these, critical theorists attempt to reveal the hidden power structures that facilitate exploitation and oppression.

This type of analysis has been used by critical theorists to evaluate how current definitions of "sustainability" and "sustainable development" might help to perpetuate systemic inequality [16]-[19]. A critical reading of the discourse on sustainability reveals that this concept is typically presented as objective, a-political, and a-cultural [7], [17]. As Lélé and Norgaard discuss, one cannot define sustainability without making a series of value judgements regarding what ought to be sustained, in what form, for how long, and in lieu of what other social goals [17]. When a concept's definition relies on value judgements but is framed as value neutral, only one set of values are represented [7]. When this occurs, the values that are represented are typically those of historically dominant groups, that is, wealthy, white, colonial males.

There are two lessons that Engineering educators can take from critical theory's application to sustainability and sustainable development. First, that work is already being done to assess how the discourse on sustainability and sustainable development privileges certain voices over others. This literature offers valuable insights on the power dynamics of "sustainability" and includes discussions on how educators might approach teaching sustainability in a more critical, inclusive way (see for example [7], [16], [18], [19]). The second lesson involves the dangers associated with claiming to be value neutral. Critical theory reminds us that claiming to be objective or value neutral can result in blindly endorsing systems based in oppressive ideologies and silence alternative views. As Engineering educators, we should be critical of objectivity claims and encourage our students to do the same. By allowing other voices into our classrooms, we can help to counteract systemic inequality.

\section{DISCUSSION}

\subsection{Sustainability}

To quote Nolan Dey, an Engineering graduate student at the University of Waterloo, "the definition of sustainability always seems to be the Western world's definition". Dey's comment came during one of our capstone design panel exams where a 4th year student team was working on a sustainability focussed project but failed to present a definition of sustainability. The team instead based their design and decisions on an implicit definition of sustainability that didn't examine impacts across the entire lifecycle of their solution. Instead, they focussed on 
including buzz words and general concepts of "recycling" without addressing cultural, social, and economic sustainability or a more nuanced and in-depth analysis of environmental sustainability. Sustainability for these students, who are a product of our department's courses and educational system, seems superficial and based on maintaining the status quo of the modern Western lifestyle. Dey's comment was also meant to address this Westerncentric value statement; that the students were looking at this from one perspective that views a Western definition of sustainability as superior to a definition arising from other cultures and parts of the world. The authors might suggest that this implicit "maintain our current Westernlifestyle" definition is part of a capitalist system driving consumer lifestyles in the West. These lifestyles are seemingly defined by the technology built, at least in-part, by Engineers.

The UN sponsored Brundtland Commission's definition is perhaps an example of this in its coining of the term "sustainable development" in 1987's Our Common Future as: "Sustainable development is development that meets the needs of the present without compromising the ability of future generations to meet their own needs" [20]. This definition has been criticized for being too open to interpretation, but its needs-based definition is interesting, as it inherently asks the tough question of what is "needed"? Contrasting Krenak's similarly simple definition introduced earlier in this paper, we can see a shift in the way sustainability is perceived, as maintaining, and meeting ill-defined needs, as opposed to offsetting and balancing consumption. Development includes a value judgment and assumption that "progress" and alleviating "poverty" are common goals or targets for all communities and worlds that make up our planet. What is poverty? What perspective are we defining it from? How much autonomy should people have to define their own needs outside of the Western capitalist market-based worldview that Engineers facilitate and participate in? Will economic growth be the path to meet these needs? For some it might, but for others economic growth may be a concept that doesn't have much value in their life.

Aguirre's analysis of the usage of the term "sustainable development" provides insight into multiple interpretations of sustainable development that have evolved since 1987's Brundtland Commission [5]. Initially, Aguirre sees sustainable development being taken up by the scientific community to provide motivation for creating international equity and environmental protection around the world, as a strongly environmental definition that sees environmental damage in "third world" countries as the cause and the "development" of these countries and their economies and environmental practices as the cure. After the term was introduced, it began to gain acceptance and more widespread use, but with its unspecific definition, sustainable development was open to interpretation and practical redefinition by the different groups who adopted it for application in their domain of research or policy. Prendergast's interpretation, from an Engineering perspective, that "sustainable development is an effort to use technology to help clean up the mess it helped make, and Engineers will be central players in its success or failure" demonstrates culpability and good intention, but also a technocentric perspective; that a solution to the problem will be in the form developing more technology [21]. This ownership of the problem and creation of solutions is confirmed by Wright who says "Engineers will take the lead as the managers of sustainability", an idea echoed by Illman who says "Engineers can have a greater impact on achieving sustainable development than any other profession" [22], [23]. What if Illman is right, but the way Engineers can have this impact is by halting technological development? Are Engineers over-valuing their role in solving the problems of Western capitalism that values progress, growth, and technological development so highly?

Waseem and Nato provide a recent review and analysis of sustainability definitions which concludes that among the many definitions, most are "global, non-measurable, and ambiguous" [24]. Tracing sustainability from its etymological roots in the 17 th century, meaning "bearable", to the present interpretation, as "capable of being continued at a certain level", they argue that, ultimately, we need a more measurable and clear definition that applies to different situations and contexts [24]. Categorizing sustainability, they identify five perspectives present in the definitions they analyzed: "Limits" - relating to the threshold of consumption; "Three Pillar" - relating to the environment, social, and economic; "Sustain" relating to keeping in existence, maintaining, and continuing; "Human Welfare" - relating to ensuring a universal quality of life; and "Sustainable Development" relating to a development approach that ensures sustainability [24]. The focus on these attributes have shifted over time, with sustainable development being a focus from 1987-2000, but human welfare and the more general sustain becoming the common themes in the definitions they analyzed from 2000 to present [24]. A note about their methodology should be made; they searched for definitions and found thousands of articles, but only from seven prominent academic journal publishers. Favouring academic knowledge and, in this case, doing so to the exclusion of non-academic sources, once again makes it necessary to ask anyone engaging in this area to question what assumptions and biases are built into these ideas and definitions.

Virtanen et al. argue that a more inclusive definition of sustainability is needed [25]. Working from an Indigenous studies perspective, they ask for consideration that sustainability should include "context-based relationality, community-based governance, education, language, quality of life and health, and communal recognition of certain non-humans as life givers". This autonomy and 
complex relationality echo the ideas of the pluriversal perspective introduced earlier. Virtanen et. al also explicitly reject the universality of the UN Sustainable Development Goals, as conceptual and moral differences exist in the different groups living in this world that need to be respected [25], [26]. One size doesn't fit all.

While we are moving towards an increased body of knowledge there is not a significant amount of research on best practices for contextualizing Indigenous knowledge in current Engineering practices in Canada - the statement itself being loaded in that simply by contextualizing Indigenous knowledge within Engineering, we inherently place it as separate. Meaningful inclusion of Indigenous perspectives and worldviews will positively impact developing Engineering solutions that are more equitable and address sustainability for more than just one community or market. By acknowledging that Cultural Appropriation and the Commodification of Indigenous Ways of Knowing, we can work to change our practices, frameworks, and contexts to better inspire Indigenous youth to pursue Engineering [27]. Current work in a Canadian context includes Friesen and Hermann's discussion of Engineering design and the redevelopment of courses to include Indigenous knowledge and perspectives at the University of Manitoba [28]. They convey that engaging with Indigenous design principles requires the participants to be open to a different "intellectual space", or epistemology, one that hasn't historically been discussed in Engineering institutions in Canada. The diversity of Indigenous experience across Canada is another important recognition that echoes the pluriversal ideas discussed earlier - that context and understanding aren't universal, and they will take time and effort to develop, particularly when engaging groups that have different ways of understanding and sharing knowledge. We would like to acknowledge the significant work and labour done by authors who are experts in Indigenous Knowledge, and anti-colonial practice. We strongly encourage readers to dig deeper into this work that is being done and to deeply read the suggestions below and consider how they fit into the Engineering context you approach with your teaching [3], [15], [29]- [46]

Undoubtedly there are many other definitions of sustainability, explicit or implicit, that the authors have not covered. The intention here is not to be complete, but to demonstrate and express the need to consider and understand the alternative ways we can engage with sustainability, a topic that will require more research, discussion, and learning both inside and outside the walls of our Engineering departments, institutions, and systems of knowledge.

\subsection{Design}

In terms of the application of these ideas, the design projects and design courses our students complete during their degrees are likely the best avenues to practically explore sustainability and the Engineer's role in, and effect on, the outcomes of our work in a broader and more realistic context. Engineering design methodologies typically follow a common structure consisting of an iterative cycle through problem definition, solution generation, prototyping, testing, and recommending improvements before starting the process over again [47]. Multiple iterations see the prototype and design progress from a low-fidelity stage to a high-fidelity solution that is ready to be released to the market or implemented in the real world to solve the defined problem. We can understand that sustainability is a topic we either choose to include explicitly, or, that it is already inherently part of the design problem's definition. In either case the subjectivity and perspectives associated with sustainability discussed earlier will have an effect on our students' learning and development. If we recognize our power as educators to influence the perspectives of our students, the question is then what perspective do we teach? If we avoid choosing to explicitly teach a certain perspective, do we instead implicitly assume the values built-in to the topics and ideas we work with or the way we attempt to generate solutions?

Not only the subjects and topics of design are valueladen, but also the methodologies of design. Alternative approaches to design exist in many fields, with some focussed on more inclusive and reflective design practices that would likely be useful when addressing topics like sustainability. Two of these methods are introduced below.

\subsection{Co-Design and Participatory Design}

Cooperative Design (Co-design) and Participatory Design are related ideas that have a simple basic premise and many possible forms of implementation. In both methods the people affected by the design, and the problems it intends to address, are directly included in the design process [48], [49]. This can range from simple consultation to more active co-creation and involvement in all stages of the design's development [50]. Engineering is seeing user-centered design practice be more directly incorporated into its design methods, but Participatory Design pushes this involvement further and deeper [51]. Co-design and Participatory Design find applications in service design, environmental sustainability, and social innovation design, and include practices such as storytelling to deepen the understanding between the designers and participants [49], [51]-[54].

\subsection{Discursive Design}

Discursive design is a broad term that Tharp and Tharp define as a method for creating "intellectual prostheses" [55]. It includes more specific methods, such as speculative design, critical design, and design-fiction, which have a common purpose: to communicate ideas and instigate reflection through a design intention that is not traditionally utilitarian [55]. Instead of trying to solve the problem at hand, the design outcomes are intended to question and 
challenge the understanding of the problem, the perspectives of the people, places, and things involved, and the methods and tools that can be employed to try to solve it. Collaborating with Discursive Designers presents an opportunity for the Engineering design process to incorporate more reflection and more perspectives. It also presents an opportunity to directly challenge and discuss the assumptions and complexities inherent in the complex problems Engineers work on.

\section{CONCLUSION - DEVELOPING UNDERSTANDING IN ENGINEERING}

Reflecting on our own journeys in developing understanding, it is clear that we have not yet arrived at a final destination. We haven't arrived at the answer and cannot provide a prescriptive list of things Engineering educators should do to address the effects of capitalism, patriarchy, colonialism, and the Western context that our own Engineering practice finds itself situated in. Taking inspiration from critical social theory provides a starting point: to "make strange," or approach taken-for-granted systems and knowledge with suspicion, rejecting surface level explanations of their power structures and hidden complexity. With reference to sustainability, that means questioning our own role in how we communicate the many factors and perspectives that come together when addressing something this complicated. When we teach anything, it comes value-laden; we need to pay attention to that. Organizational theory suggests that the situations we find ourselves in have a major effect on our decisionmaking processes [56]. Part of this process is the "logic of appropriateness", an approach used to describe and predict how people will actually behave in social situations. In contrast to a "logic of consequence", where individuals are expected to make decisions based on the maximum utility of an outcome, the logic of appropriateness suggests that most decisions are made based on what people believe is appropriate in terms of the social rules of how we should act in a given context the moment the decision is made. In a world of fake news, alternative facts, social media echo chambers, and the insta-success of Tekashi 6ix9ine, how do we as educators choose to take on the responsibility of developing the social expectation of what is appropriate in the opportunities we have as Engineering role-models and educators for our students [57]? We also shouldn't forget that those opportunities also exist with our colleagues, in our meetings, in the hallways when we run into students, and when we reach out and interact with people from other parts of our campus. A simple suggestion is to make room and time for "social sustainability" in the problem space when we develop design projects and course content [18]. To make room for interactions with colleagues and students from other disciplines on our campus. To make room for discussions and participation with people on and off our campuses, who bring with them knowledge and lived experience in many different forms [6], [9]. All too often the pressure of meeting expectations around course content, the CEAB accreditation process, and the general culture of Engineering education means that we struggle to find the opportunities for these things. In this inherently slow-to-change system what doesn't have to be slow to change are the small parts of our practice we have control over and the work we can do to learn about, respect, and understand the world of many worlds that exist on this planet.

\section{References}

[1] A. Escobar, "Sustainability: Design for the pluriverse," Development, vol. 54, no. 2, pp. 137140, 2011, Accessed: Mar. 03, 2021. [Online]. Available:

https://ideas.repec.org/a/pal/develp/v54y2011i2p1 37-140.html.

[2] A. Escobar, Duke University Press - Designs for the Pluriverse. Chapell Hill: Duke University Press, 2018.

[3] E. Galeano, Open Veins of Latin America: Five Centuries of the Pillage of a Continent. New York : Monthly Review Press, 1997.

[4] P. Glavič and R. Lukman, "Review of sustainability terms and their definitions," Journal of Cleaner Production, vol. 15, no. 18, pp. 18751885, Dec. 2007, doi: 10.1016/j.jclepro.2006.12.006.

[5] B. E. Aguirre, "'Sustainable Development' as Collective Surge," Social Science Quarterly, vol. 83, no. 1, pp. 101-118, Mar. 2002, doi: 10.1111/1540-6237.00073.

[6] G. W. Misiaszek, "Ecopedagogy: teaching critical literacies of 'development", "sustainability", and 'sustainable development',,"," Teaching in Higher Education, vol. 25, no. 5, pp. 615-632, 2020, doi: 10.1080/13562517.2019.1586668.

[7] F. D. S. Ferreira, "Critical sustainability studies : A holistic and visionary conception of socioecological conscientization," Journal of Sustainable Education, vol. 13, no. March, pp. 121, 2017.

[8] E. Paradis, L. Nimmon, D. Wondimagegn, and C. R. Whitehead, "Critical Theory: Broadening Our Thinking to Explore the Structural Factors at Play in Health Professions Education," Academic Medicine, vol. 95, no. 6, pp. 842-845, 2020, doi: 10.1097/ACM.0000000000003108.

[9] J. Bardzell, S. Bardzell, and M. A. Blythe, Critical Theory and Interaction Design. MIT Press, 2018.

[10] A. Krenak, Ideas to Postpone the End of the World - House of Anansi Press. Toronto, ON: House of Anansi , 2020. 
[11] W. Mcdonough and M. Braungart, Cradle to Cradle: Remaking the Way We Make Things, Bo. New York City: Farrar, Straus And Giroux, 2002.

[12] M. de la Cadena and M. Blaser, Duke University Press - A World of Many Worlds. Chapell Hill: Duke University Press, 2018.

[13] R. Macleod, "Colonial engineers and the 'cult of practicality': Themes and dimensions in the history of Australian engineering," History and Technology, vol. 12, no. 2, pp. 147-162, Jan. 1995, doi: 10.1080/07341519508581881.

[14] "Environmental personhood - Wikipedia." https://en.wikipedia.org/wiki/Environmental_pers onhood (accessed Mar. 03, 2021).

[15] "New Zealand River is given status as a 'legal person," Metro, Mar. 2017, Accessed: Mar. 03, 2021. [Online]. Available: https://metro.co.uk/2017/03/16/whanganui-riverbecomes-first-in-the-world-to-be-recognised-as-alegal-person-6512264/.

[16] Z. Walsh, J. Böhme, and C. Wamsler, "Towards a relational paradigm in sustainability research, practice, and education," Ambio, vol. 50, no. 1, pp. 74-84, 2021, doi: 10.1007/s13280-020-01322-y.

[17] S. Lele and R. B. Norgaard, "Society for Conservation Biology Sustainability and the Scientist's," Biology, vol. 10, no. 2, pp. 354-365, 1996.

[18] R. Hollander et al., "Network priorities for social sustainability research and education: Memorandum of the Integrated Network on Social Sustainability Research Group," Sustainability: Science, Practice, and Policy, vol. 12, no. 1, Mar. 2016, doi: 10.1080/15487733.2016.11908150.

[19] M. Watts, Z. Jofili, and R. Bezerra, "A case for critical constructivism and critical thinking in science education," Research in Science Education, vol. 27, no. 2, pp. 309-322, 1997, doi: 10.1007/BF02461323.

[20] World Commission on Environment and Development, Our Common Future. New York, NY: Oxford University Press, 1987.

[21] J. Prendergast, "Engineering sustainable development ," Civil Engineering , vol. 63, no. 10, Oct. 1993, Accessed: Mar. 03, 2021. [Online].

[22] D. W. Wright, "Infrastructure Planning and Sustainable Development," Journal of Urban Planning and Development, vol. 122, no. 4, pp. 111-117, Dec. 1996, doi: 10.1061/(asce)07339488(1996)122:4(111).

[23] D. L. Illman, "Engineers take up challenge of sustainable development," Chemical and Engineering News, vol. 71, no. 37. American Chemical Society , pp. 35-37, 1993, doi: 10.1021/cen-v071n037.p035.

CEEA-ACEG21; Paper 125

University of Prince Edward Island; June $21-23,2021-7$ of 8 -
[24] N. Waseem and S. Kota, "Sustainability definitions - an analysis," in Smart Innovation, Systems and Technologies, 2017, vol. 66, pp. 361371, doi: 10.1007/978-981-10-3521-0_31.

[25] P. K. Virtanen, L. Siragusa, and H. Guttorm, "Introduction: toward more inclusive definitions of sustainability," Current Opinion in Environmental Sustainability, vol. 43. Elsevier B.V., pp. 77-82, Apr. 01, 2020, doi: 10.1016/j.cosust.2020.04.003.

[26] “THE 17 GOALS | Sustainable Development." https://sdgs.un.org/goals (accessed Mar. 03, 2021).

[27] D. Burgart, "Indigeneering: The Future of Engineering Education,” Jun. 2020, Accessed: Mar. 03, 2021. [Online]. Available: https://diversity.asee.org/deicommittee/2020/05/2 $0 /$ indigeneering-the-future-of-engineeringeducation/.

[28] M. R. Friesen and R. Herrmann, "Indigenous Knowledge, Perspectives, and Design Principles in the Engineering Curriculum," Proceedings of the Canadian Engineering Education Association (CEEA), Dec. 2018, doi: 10.24908/pceea.v0i0.12964.

[29] D. M. Nadeau, Unsettling Spirit: A Journey into Decolonization. McGill-Queen's Press-MQUP, 2020.

[30] S. Maddison, "Indigenous autonomy matters: what's wrong with the Australian government's 'intervention'in Aboriginal communities," Australian Journal of Human Rights, vol. 14, no. 1, pp. 41-61, 2008.

[31] C. Fortier, "Unsettling the Commons," Social Movements Within, Against, and Beyond Settler Colonialism. Winnipeg: Arp Books, 2017.

[32] J. Tockman and J. Cameron, "Indigenous autonomy and the contradictions of plurinationalism in Bolivia," Latin American Politics and Society, vol. 56, no. 3, pp. 46-69, 2014.

[33] T. Gonzales and M. González, "Introduction: Indigenous peoples and autonomy in Latin America," Latin American and Caribbean Ethnic Studies, vol. 10, no. 1, pp. 1-9, 2015.

[34] C. Royal, "Let the World Speak': Towards Indigenous Epistemology," Te Kaim $\wedge=$ a)nga: Towards a New Vision for $M_{\wedge}=a$ ) tauanga $M \wedge=$ a fori, 2009.

[35] M. B. E. Held, "Decolonizing research paradigms in the context of settler colonialism: an unsettling, mutual, and collaborative effort," International Journal of Qualitative Methods, vol. 18, p. $1609406918821574,2019$.

[36] C. Fortier, "Unsettling methodologies/decolonizing movements," Journal of Indigenous Social Development, vol. 6, no. 1, 2017. 
[37] D. Foley and others, "Indigenous epistemology and Indigenous standpoint theory," Social alternatives, vol. 22, no. 1, p. 44, 2003.

[38] A. H. Macfarlane, T. Glynn, W. Grace, W. Penetito, and S. Bateman, "Indigenous epistemology in a national curriculum framework?," Ethnicities, vol. 8, no. 1, pp. 102126, 2008.

[39] R. Stavenhagen, "Indigenous peoples: Land, territory, autonomy, and self-determination," ROSSET, P.; PATEL, R.; COURVILLE, M. Promised Land: Competing Visions of Agrarian Reform. Oakland, CA: Food First Books, pp. 208211, 2006.

[40] S. Samuel, "Lake Erie now has legal rights, just like you," Vox, Feb. 2019, Accessed: Mar. 03, 2021. [Online]. Available: https://www.vox.com/futureperfect/2019/2/26/18241904/lake-erie-legalrights-personhood-nature-environment-toledoohio.

[41] K. Ragoonaden and L. Mueller, "Culturally Responsive Pedagogy: Indigenizing Curriculum, Canadian Journal of Higher Education, 2017," Canadian Journal of Higher Education, vol. 47, no. 2, pp. 22-46, 2017, Accessed: Mar. 03, 2021. [Online]. Available: https://eric.ed.gov/?id=EJ1154077.

[42] L. Peach, C. A. M. Richmond, and C. BrunetteDebassige, "'You can't just take a piece of land from the university and build a garden on it': Exploring Indigenizing space and place in a settler Canadian university context," Geoforum, vol. 114, pp. 117-127, Aug. 2020, doi: 10.1016/j.geoforum.2020.06.001.

[43] E. Sumida Huaman and P. Mataira, "Beyond community engagement: centering research through Indigenous epistemologies and peoplehood," AlterNative, vol. 15, no. 3. SAGE Publications Inc., pp. 281-286, Sep. 01, 2019, doi: 10.1177/1177180119871705.

[44] A. Gaudry and D. Lorenz, "Indigenization as inclusion, reconciliation, and decolonization: navigating the different visions for indigenizing the Canadian Academy," AlterNative: An International Journal of Indigenous Peoples, vol. 14, no. 3, pp. 218-227, Sep. 2018, doi: $10.1177 / 1177180118785382$.

[45] N. Ineese-Nash, "Is resistance enough? Reflections of identity, politics, and relations in the 'in-between' spaces of Indigeneity and settlerhood," AlterNative, vol. 16, no. 1, pp. 10-17, Mar. 2020, doi: 10.1177/1177180119878239.

[46] R. Sinclair, "Aboriginal Social Work Education in Canada: Decolonizing Pedagogy for the Seventh Generation," First Peoples Child \& Family
Review, vol. 1, no. 1, pp. 49-61, May 2020, doi: 10.7202/1069584ar.

[47] C. L. Dym, Engineering Design: A Project-Based Introduction, 4th ed. Toronto: Wiley, 2013.

[48] M. Steen, "Co-design as a process of joint inquiry and imagination," Design Issues, vol. 29, no. 2, pp. 16-28, 2013.

[49] T. Robertson and J. Simonsen, "Participatory design," Routledge international handbook of participatory design, p. 1, 2012.

[50] E. B.-N. Sanders and P. J. Stappers, "Co-creation and the new landscapes of design," Co-design, vol. 4, no. 1, pp. 5-18, 2008.

[51] D. Schuler and A. Namioka, Participatory design: Principles and practices. CRC Press, 1993.

[52] A. Kankainen, K. Vaajakallio, V. Kantola, and T. Mattelmäki, "Storytelling Group--a co-design method for service design," Behaviour \& Information Technology, vol. 31, no. 3, pp. 221230, 2012.

[53] E. Manzini, Design, when everybody designs: An introduction to design for social innovation. MIT press, 2015.

[54] E. Manzini and F. Rizzo, "Small projects/large changes: Participatory design as an open participated process," CoDesign, vol. 7, no. 3-4, pp. 199-215, 2011.

[55] S. A. Barab, "Critical Design Ethnography: Designing for Change," Anthropology <html_ent glyph="@amp;" ascii="\&amp;"/> Education Quarterly, vol. 35, no. 2, pp. 254-268, Jun. 2004, doi: 10.1525/aeq.2004.35.2.254.

[56] J. M. Weber, "Individuals matter, but the situation's the thing: The case for a habitual situational lens in leadership and organizational decision-making ," Organizational Dynamics, 2019, doi: 10.1016/j.orgdyn.2019.03.003.

[57] R. A. Roks, “'Keeping It (Hyper)Real': A Musical History of Rap's Quest Beyond Authenticity," in Crime and Music, Springer International Publishing, 2021, pp. 271-285. 